\title{
Prevalence of allergic rhinitis in children with otitis media with effusion
}

\author{
Department of Otorhinolaryngology, Head and Neck Surgery, Hospital Canselor Tuanku Mukhriz, Universiti Kebangsaan
} Malaysia, Kuala Lumpur, Malaysia

\section{KEY WORDS \\ allergic rhinitis; allergens; deafness; hearing loss; otitis media with effusion; prevalence; risk factors}

\author{
Corresponding author \\ Bee See Goh \\ Department of Otorhinolaryngology \\ Head and Neck Surgery \\ Faculty of Medicine \\ Universiti Kebangsaan Malaysia \\ Hospital Jalan Yaacob Latif \\ 56000 Cheras \\ Kuala Lumpur, Malaysia \\ E-mail : beesee@ppukm.ukm.edu.my; \\ irenegbs@yahoo.com \\ Phone: +60391456045 \\ Fax: +60391456 675 \\ Doi \\ 10.23822/EurAnnACI.1764-1489.119
}

\begin{abstract}
Summary
Introduction. The prevalence of allergic rhinitis in children with persistent otitis media with effusion in different countries varies between $82 \%$ to 93\%. Many risk factors of otitis media with effusion has been studied and proven. However, its association with allergic rhinitis remains controversial. Objective. The main objective of this study is to determine the prevalence of allergic rhinitis in children with persistent otitis media with effusion. This study is also aimed to identify the risk factors of otitis media with effusion, common allergens associated with allergic rhinitis and determine the hearing threshold of children with otitis media with effusion. Methods. A hundred and thirty children were recruited. History taking, physical examination and hearing assessment were done in the first visit. Those with allergic rhinitis underwent skin

prick test and treated with intranasal corticosteroid and antihistamine. A second examination and hearing assessment were then repeated after 3 months. Results. The prevalence of allergic rhinitis in children with persistent otitis media with effusion in this study was noted to be 80.3\%. Among these children, dust mites appeared to be the most common allergen (87.7\%). Another risk factor appeared to be families with more than 4 members per-household (96\%). It is noted that that otitis media with effusion caused a hearing loss up to $33 \mathrm{~dB}$. However, there was a statistically significant improvement of the hearing threshold during second visit after commencement of allergy treatment. It was also noted that the hearing threshold in allergic rhinitis group was significantly impaired compared to the non-allergic rhinitis group. Conclusions. Allergic rhinitis and larger family household appeared to be common risk factors in children with persistent otitis media with effusion. There is significant hearing loss noted in children suffering from otitis media with effusion and allergic rhinitis. The hearing threshold improved remarkably with medical therapy. This study hence clarifies the controversy on the association between allergic rhinitis and otitis media with effusion.
\end{abstract}

\section{Introduction}

Otitis media with effusion (OME) is defined as inflammation of the mucous membrane with fluid collection in the middle ear in the absence of acute infection (1). The pathogenesis of OME can be multifactorial, it involves infection of the tubotympanum, eustachian tube dysfunction and allergy (2).

Prevalence of OME among children in different countries varies between $6.5 \%$ to $10.9 \%$ (3). A local study done by Saim A et al. in 1997 reported the overall prevalence of OME among the preschool children to be $13.8 \%$. The prevalence is noted to be higher in Kuala Lumpur (17.9\%) compared to the district of Kuala Selangor (9.5\%) (4). National Hearing Survey for hearing and ear disorder in Malaysia showed the prevalence of OME to be $5.1 \%$ in the general population, $2.9 \%$ in children below 10 years old and $2.6 \%$ in children aged 10 to 19 years (5). The prevalence of persistent $\mathrm{OME}$ on the other hand was reported as high as $8.7 \%$ in Turkey (3). However, similar study has yet to be reported locally or regionally (3).

There are several factors that influence the development of OME. Non-medical risk factors include age, large family size, history of OME in a sibling, short duration or no breastfeeding 
and passive smoking. Medical risk factors include the history of acute otitis media (AOM), allergic rhinitis (AR), history of acute tonsillitis and craniofacial anomalies (6).

The association between AR and OME has been a controversial issue with many contradicting results. In a study conducted by Fernadez and McGovern on 113 children with OME, 83\% were found to be have allergy based on history and $92 \%$ had positive skin prick test (7). Alles $\mathrm{R}$ et al. studied on the prevalence of atopic disorders in 209 children with OME and they found $89 \%$ had AR (8). Passali D et al. reported that children with persistent OME and AR were found to have eustachian tube (ET) dysfunction (9). Allergic rhinitis can cause swelling of nasal mucosa resulting in eustachian tube dysfunction and subsequently leading to OME (10).

The Malaysian Clinical Practice Guidelines on Management of OME in children recommends surgical intervention to be considered after three months of OME with hearing loss of more than $25 \mathrm{~dB}$ (average frequency of three) and/or structural changes to the tympanic membrane or middle ear. Myringotomy with ventilation tube insertion is recommended as the surgical treatment of choice (6).

Persistent fluid in the middle ear cavity may form a barrier for sound conduction affects the threshold acuity (11). If left untreated, OME may be complicated with hearing loss especially conductive type, vestibular problem, poor school performance, behavioral problems, recurrent acute otitis media and reduce the quality of life (12).

\section{Objectives}

This study aimed to determine the prevalence of allergic rhinitis (AR) in children with persistent OME in Universiti Kebangsaan Malaysia, Medical Centre (UKMMC). It is also conducted to identify the risk factors, common allergens and hearing threshold in children with OME.

\section{Materials and methods}

\section{Study Instruments}

\section{Otoscope}

An otoscope is used to visualize the tympanic membrane to identify middle ear effusion as defined by a dull appearance of the tympanic membrane with the presence of air-fluid level or air bubbles.

\section{Conventional $(226 \mathrm{~Hz})$ tympanometry}

This test was carried out by an audiologist and a researcher. A tympanometer was used to measure the compliance of the tympanic membrane. It contained an earpiece which was introduced into the ear canal. A miniature loudspeaker generated a $226 \mathrm{~Hz}$ probe tone which was reflected off the tympanic mem- brane. The data was generated in a graph which was interpreted as normal (type A), flat or decreased maximum tympanic membrane compliance (type B) or of negative middle ear pressure (types C). Decreased mobility of the tympanic membrane is due to effusion in the middle ear and it is the most common cause of type B tympanogram. Tympanograms were labeled as type $C$ if there is a presence of a significant negative pressure which indicate eustachian tube dysfunction. For this study, type B tympanogram with normal ear canal volume was considered as otitis media with effusion.

\section{Hearing assessment}

Play audiometry and pure tone audiometry were the hearing assessment used depending on the ability of the child to understand the task. Hearing assessment for pure tone audiometry was done at $250 \mathrm{~Hz}, 500 \mathrm{~Hz}, 1 \mathrm{kHz}, 2 \mathrm{kHZ}, 4 \mathrm{kHz}$, and 8 $\mathrm{kHz}$. The level of severity of hearing loss was defined as follows, mild hearing loss 26 - $40 \mathrm{dBHL}$, moderate hearing loss 41 - 70 $\mathrm{dBHL}$, severe hearing loss $71-90 \mathrm{dBHL}$, and profound hearing loss was $>90 \mathrm{dBHL}$.

\section{Skin prick test (SPT)}

Skin prick test was performed on all subjects with AR by an otorhinolaryngology doctor. The skin area on the inner forearm was labeled with codes to identify tested allergens. A drop of the allergen solution was placed on the skin. The skin was then pricked through the drop using the tip of a lancet. Reading on the result was done after 20 minutes and the size of the wheals was outlined with a felt tip pen and transferred to the recording sheet by adhesive transparent tape. A positive result was considered if the size of the wheal was $3 \mathrm{~mm}$ or more. Common aeroallergen and food allergens were done according to a previous study done in UKMMC (13).

\section{Rigid nasal endoscopy / flexible nasopharyngolaryngoscopy}

Rigid nasal endoscopy or flexible nasopharyngolaryngoscopy was performed by the researcher or trained medical officer. $\mathrm{Na}$ sopharynx was assessed for adenoid hypertrophy. Adenoid hypertrophy was graded based on the grading system described by Cassano et al. (14), as follows:

Grade 1: the adenoid occupying upper segment of the nasopharynx ( $<25 \%$ of choana);

Grade 2: adenoid tissue occupying the upper half of the nasopharynx $(\geq 25$ to $<50 \%)$;

Grade 3: adenoid extending over nasopharynx with obstruction choana and partially the tube ( $\geq 50$ to $<75 \%$ );

Grade 4: total choanal obstruction ( $\geq 75$ to $100 \%)$.

\section{Methodology}

This study is a prospective cross-sectional study. The permission to carry out the study was obtained from the ethics and 
research committee of UKMMC with a code number of FF2016-380. Doctors and audiologists had been explained regarding the methodology prior to obtaining patients for the study. All subjects who fulfilled the inclusion and exclusion criteria for OME were identified. The research had been explained to patients or their guardians and informed consent was obtained. Information sheets with details on the study, available in Malay or English languages was provided to the parents or guardians In this study, data was extracted from the first 2 hospital visits. During the first visit, a thorough history on AR was obtained based on the Allergic Rhinitis and Its Impact on Asthma (ARIA) Guidelines 2010. Antihistamine and intranasal steroid were given to patient with AR according to the guidelines The AR symptoms were classified into 4 groups which are intermittent mild AR, intermittent moderate-severe AR, persistent mild AR, persistent moderate-severe AR (15).

During physical examination, patients' ear canals were examined with an otoscope. Patients with dull tympanic membrane or presence of air bubbles were considered to have abnormal otoscopic examination. These patients were subsequently tested for tympanometry and unilateral or bilateral type B tympanometry patients with normal ear canal volume were diagnosed to have OME. Subsequently, they underwent hearing assessment and nasal endoscopy to evaluate the size of adenoids. All patients diagnosed with AR underwent skin prick test.

After 3 months, patients were re-examined with an otoscope and tympanometry. During this follow-up, patients who had resolved OME were discharged. Hearing assessment was performed for patients with persistent type B. Courtesy phone calls were made during the period of 3 months until second visit to ensure the subjects and to reinforce on the compliance of medications.

\section{Results}

\section{Patient population}

One-hundred and fifty children with OME were identified during study duration of 10 months. However, due to default in follow up only 130 were recruited for this study. Mean age at presentation was 8.79 years old with (standard deviation \pm 3.76 years). Minimal age was 4 years old and the maximum age was 18 years old. Fifty-three percent of children with OME (70/130) were 4-8 years old, 33.8\% (44/130) were 9-13 years old and $12.3 \%(16 / 130)$ aged 14-18 years old (figure 1). Otitis media with effusion was significantly higher in 4-8 years old group compared to the older children. Sixty-seven children were male $(51.5 \%)$ and 63 children (48.5\%) were female (figure 2). The male to female ratio was 1.06:1 but the difference was not statistically significant.

In our study, the prevalence of $\mathrm{AR}$ in OME children was $52.3 \%$ (68/130). Among 68 OME children with AR, 13.2\% (9/68) had intermittent mild AR, 25.0\% (17/68) had intermittent moderate-severe AR, 29.4\% (20/68) had persistent mild AR and $33.8 \%(23 / 68)$ had persistent moderate-severe AR (figure 3).

After 3 months, among 130 children with OME, 71/130 (54.6\%) had persistent OME and 59/130 (45.4\%) had resolved OME. We found that among the persistent OME group, 57/71 $(80.3 \%)$ of children had AR. This study showed that AR is a statistically significant risk factor for developing persistent $\mathrm{OME}$ $(\mathrm{p}<0.0001)$ (table II).

The most significant presenting complaint among children with persistent OME was reduced hearing $81.7 \%$ compared to $52.5 \%$

Figure 1 - Age distribution of children with OME.

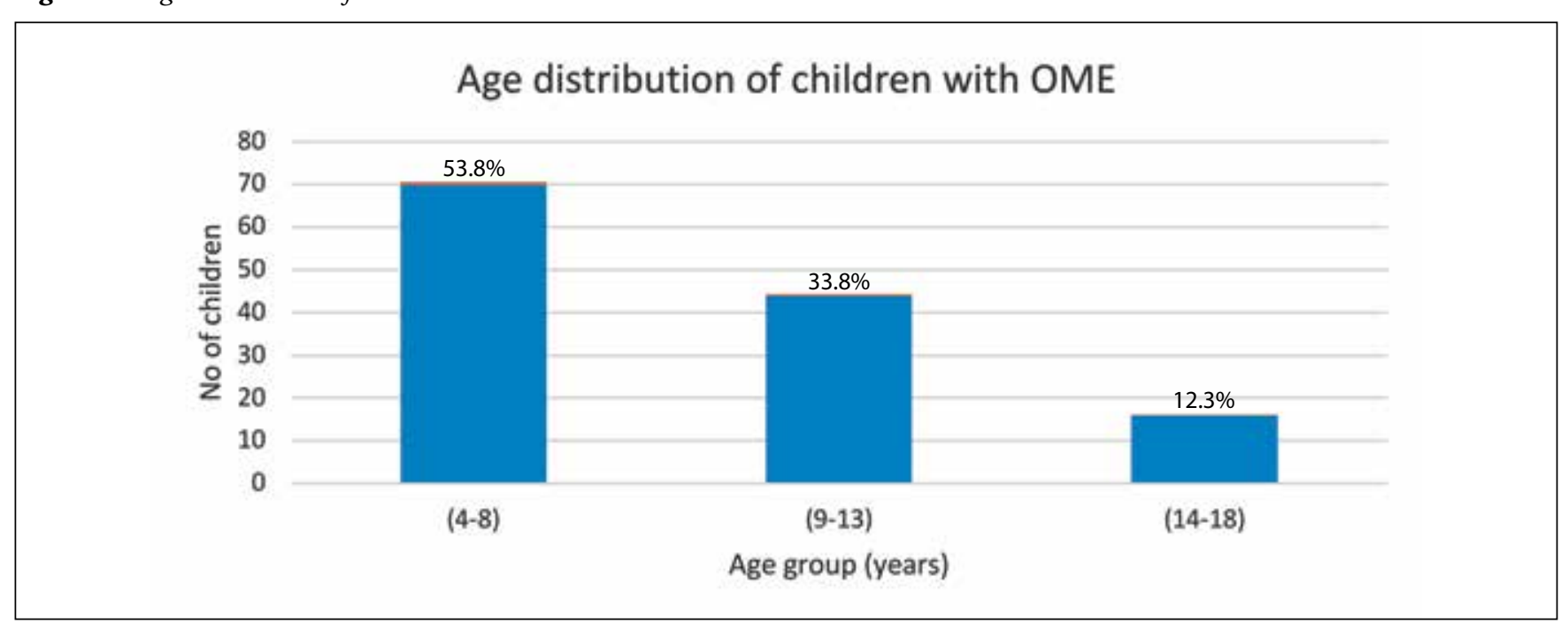


Figure 2 - Gender distribution in children with OME.

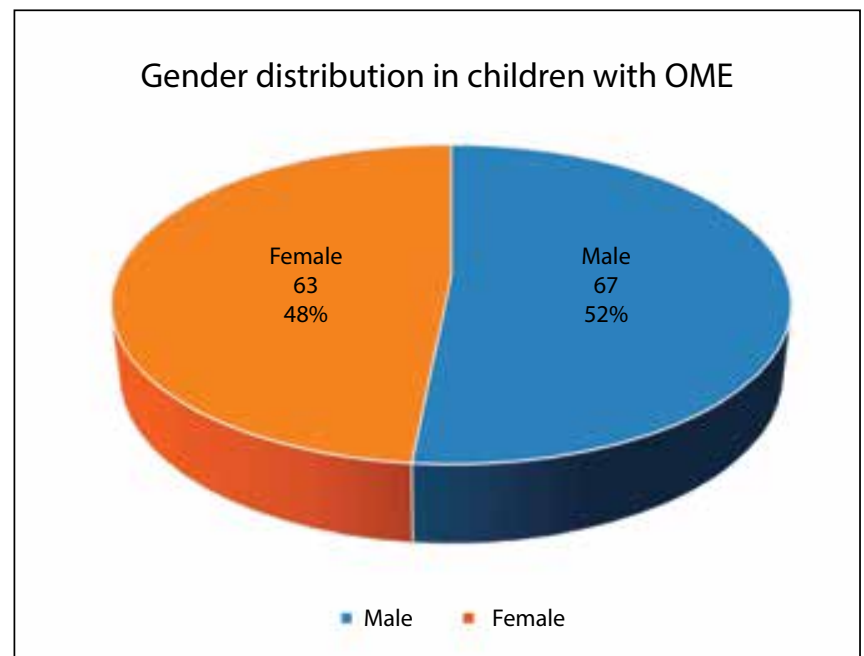

of children with non-persistent OME ( $<$ 0.0001) (table I). Family size was statistically significant influence on developing persistent OME. It was less common in the small families $(<3$ family members) than in the bigger families. Ninety-six percent (68/71) of children with persistent OME had more than 4 family members in the household. The history of OME in siblings proved a significant risk factor on developing persistent OME. The results showed that $25 \%$ of those with persistent OME had
Figure 3 - Classification of Allergic Rhinitis.

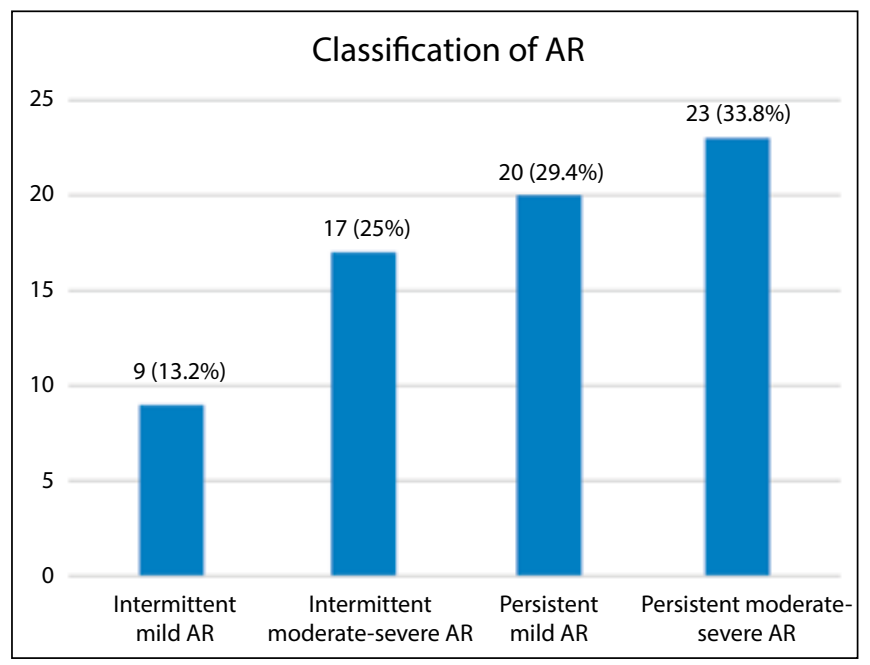

siblings with history of OME compared to $11.9 \%$ of children with non-persistent OME ( $\mathrm{p}=0.04)$ (table II).

In our study, the history of tonsillitis was not a significant risk factor for developing persistent OME. Twenty-five percent of those with persistent OME had the history of tonsillitis compared to $16.9 \%$ of children with non-persistent OME and this was not statistically significant $(\mathrm{p}=0.24)$. Regarding the history of AOM infection, $8.5 \%$ of children in both groups had a

Table I - Symptoms of OME in Children.

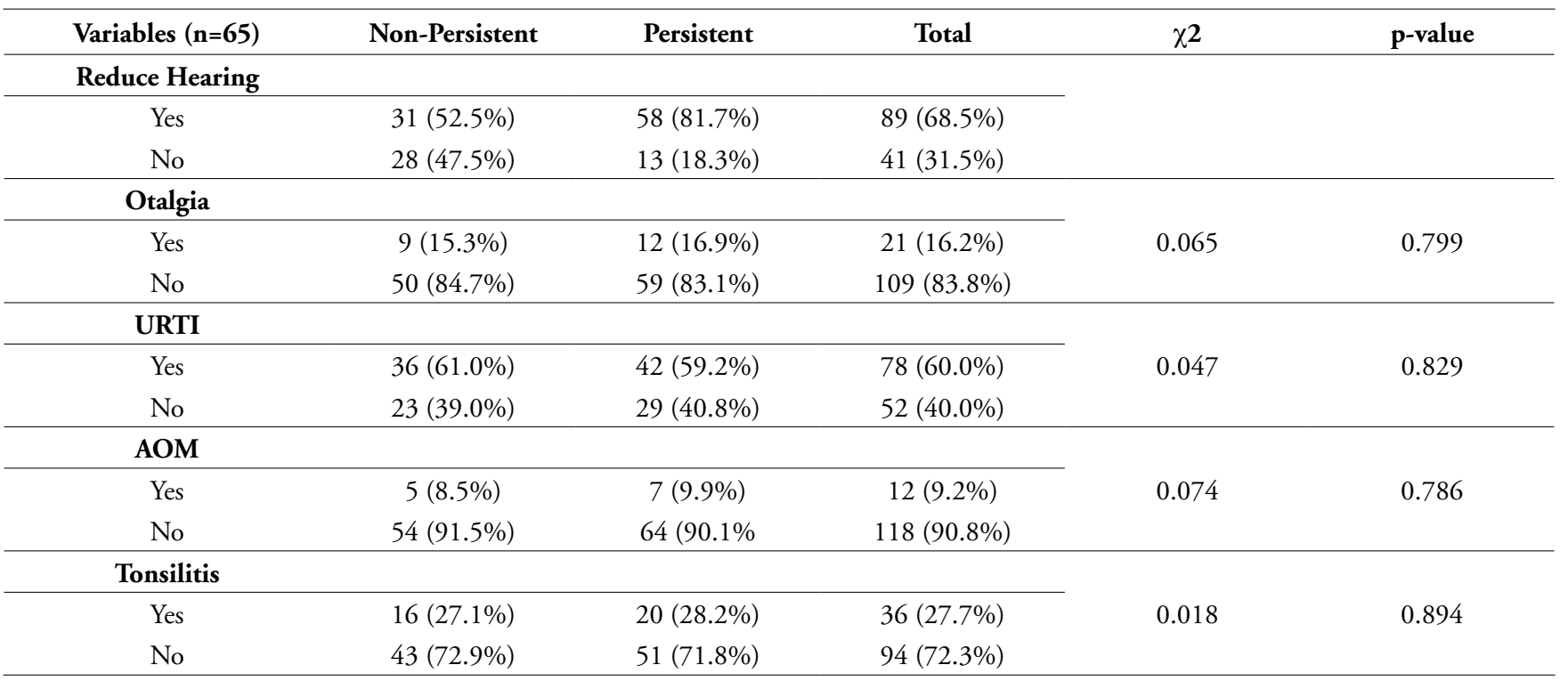


Table II - Risk factors of Children with OME.

\begin{tabular}{|c|c|c|c|c|c|}
\hline Variables $(n=65)$ & Non-Persistent & Persistent & Total & $\chi^{2}$ & p-value \\
\hline \multicolumn{6}{|c|}{ History of OME Siblings } \\
\hline Yes & $7(11.9 \%)$ & $18(25.4 \%)$ & $25(19.2 \%)$ & 3.774 & 0.052 \\
\hline \multicolumn{4}{|l|}{ Allergic Rhinitis } & \multirow[b]{2}{*}{49.073} & \multirow[b]{2}{*}{$*^{*}<0.000$} \\
\hline Yes & $48(81.4)$ & $14(19.7)$ & $62(47.7)$ & & \\
\hline \multicolumn{4}{|l|}{ Passive Smoking } & \multirow{3}{*}{0.95} & \multirow{3}{*}{0.33} \\
\hline Yes & $20(33.9 \%)$ & $30(42.3 \%)$ & $50(38.5 \%)$ & & \\
\hline No & $39(66.1 \%)$ & $41(57.7 \%)$ & $80(61.5 \%)$ & & \\
\hline \multicolumn{4}{|c|}{ History of Tonsillitis } & 1.346 & 0.246 \\
\hline$<6$ months & $15(25.4 \%)$ & $20(28.2 \%)$ & $35(26.9 \%)$ & \multirow[t]{2}{*}{0.123} & \multirow[t]{2}{*}{0.725} \\
\hline \multicolumn{4}{|l|}{$\geq 6$ months } & & \\
\hline \multicolumn{4}{|l|}{ Family Size } & \multirow{3}{*}{$\begin{array}{c}\text { Fisher's exact } \\
\text { test }\end{array}$} & \multirow{3}{*}{${ }^{*} \mathbf{0 . 0 2 0}$} \\
\hline$\leq 3$ people & $10(16.9 \%)$ & $3(4.2 \%)$ & $13(10.0 \%)$ & & \\
\hline$>3$ people & $49(83.1 \%)$ & $68(95.8 \%)$ & $117(90.0 \%)$ & & \\
\hline \multicolumn{4}{|l|}{ History of AOM } & \multirow{3}{*}{$\begin{array}{c}\text { Fisher's exact } \\
\text { test }\end{array}$} & \multirow{3}{*}{1} \\
\hline Yes & $5(8.5 \%)$ & $6(8.5 \%)$ & $11(8.5 \%)$ & & \\
\hline No & $54(91.5 \%)$ & $65(91.5 \%)$ & $119(91.5 \%)$ & & \\
\hline
\end{tabular}

history of AOM infection and this was not statistically significant $(\mathrm{p}=1.00)$ (table II). History of exposure to cigarette smokes or passive smoker showed no significant association between two groups ( $\mathrm{p}=0.33$ ), $42.3 \%$ of children with persistent OME has been exposed to smokes compared to $33.9 \%$ of children with non-persistent OME. Duration of breastfeeding was also not statistically significant in developing OME in both persistent and non-persistent group ( $\mathrm{p}=0.725)$ (table II).

In this study, we did not include the OME children with grade 4 adenoid as it is one of the confounding factors in developing persistent OME. Among the 130 children recruited, $8(6.2 \%)$ children had adenoid grade 1, 107 (82.3\%) had grade 2 and 15 (11.5\%) had grade 3 (figure 4).
Figure 4 - Adenoid Size of Children with OME.

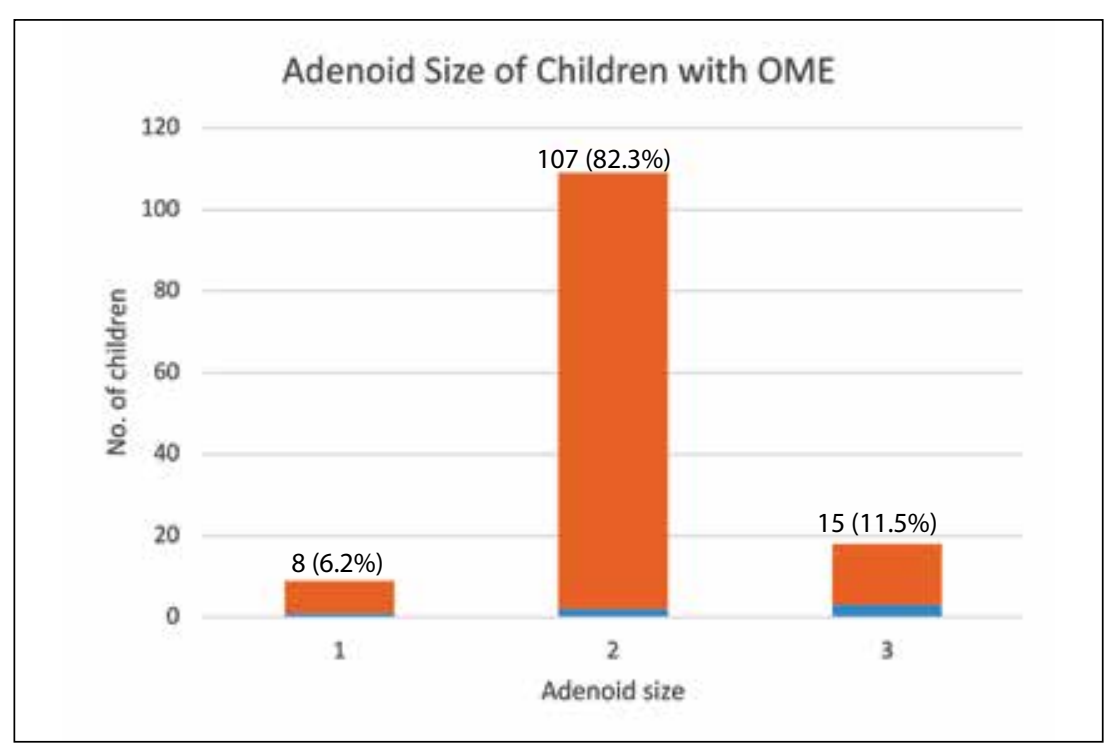


Sixty-five out of 68 children with AR underwent skin prick test to evaluate the sensitivity to the common allergens. From this test, the 3 most common allergens were Dermatophagoides pteronyssinus (DP) 87.7\%, Dermatophagoides farinae (DF) $86.2 \%$ and Blomia tropicalis $63.1 \%$ which are all aeroallergens. For food allergy, it is noted that $40 \%$ were allergic to prawn and crab, followed by $33.8 \%$ to squid, $16.9 \%$ to fish and $15.4 \%$ to chicken meat as shown in figure 5.

\section{Hearing Thresholds}

Two hundred thirty ears of children with OME were assessed with pure tone audiometry. The mean of hearing threshold for visit 1 and visit 2 were analyzed. In visit 1 , the mean frequency and standard deviation of $250 \mathrm{~Hz}, 500 \mathrm{~Hz}, 1 \mathrm{k}, 2 \mathrm{k}$,
$4 \mathrm{k}$ and $8 \mathrm{k}$ in the right ear were $33.38 \mathrm{~dB}$ (12.96), 33.50 $\mathrm{dB}$ (12.22), $32.74 \mathrm{~dB}$ (12.86), $29.36 \mathrm{~dB}$ (12.20), $28.76 \mathrm{~dB}$ (13.80), $28.68 \mathrm{~dB}$ (12.34) respectively. The mean frequency and standard deviation of $250 \mathrm{~Hz}, 500 \mathrm{~Hz}, 1 \mathrm{k}, 2 \mathrm{k}, 4 \mathrm{k}$ and $8 \mathrm{k}$ in the left ear were $33.32 \mathrm{~dB}(13.10), 33.75 \mathrm{~dB}$ (12.84), $33.41 \mathrm{~dB}$ (13.05), $30.00 \mathrm{~dB}$ (12.54), $29.47 \mathrm{~dB}$ (13.45) and $28.76 \mathrm{~dB}$ (12.53), respectively. There were no significant differences across almost all frequencies between the right and left ears (table III).

After 3 months (Visit 2), the mean of every frequency was analyzed again. The mean and standard deviation of $250 \mathrm{~Hz}, 500$ $\mathrm{Hz}, 1 \mathrm{k}, 2 \mathrm{k}, 4 \mathrm{k}$ and $8 \mathrm{k}$ in the right ear were $28.50 \mathrm{~dB}$ (12.87), $29.79 \mathrm{~dB}$ (12.97), 28.29 dB (13.17), $25.00 \mathrm{~dB}$ (12.46), 25.98 $\mathrm{dB}(13.02)$, and $24.70 \mathrm{~dB}(12.26)$, respectively. The mean and standard deviation of $250 \mathrm{~Hz}, 500 \mathrm{~Hz}, 1 \mathrm{k}, 2 \mathrm{k}, 4 \mathrm{k}$ and $8 \mathrm{k}$

Figure 5 - Positive Skin Prick Test for Allergens.

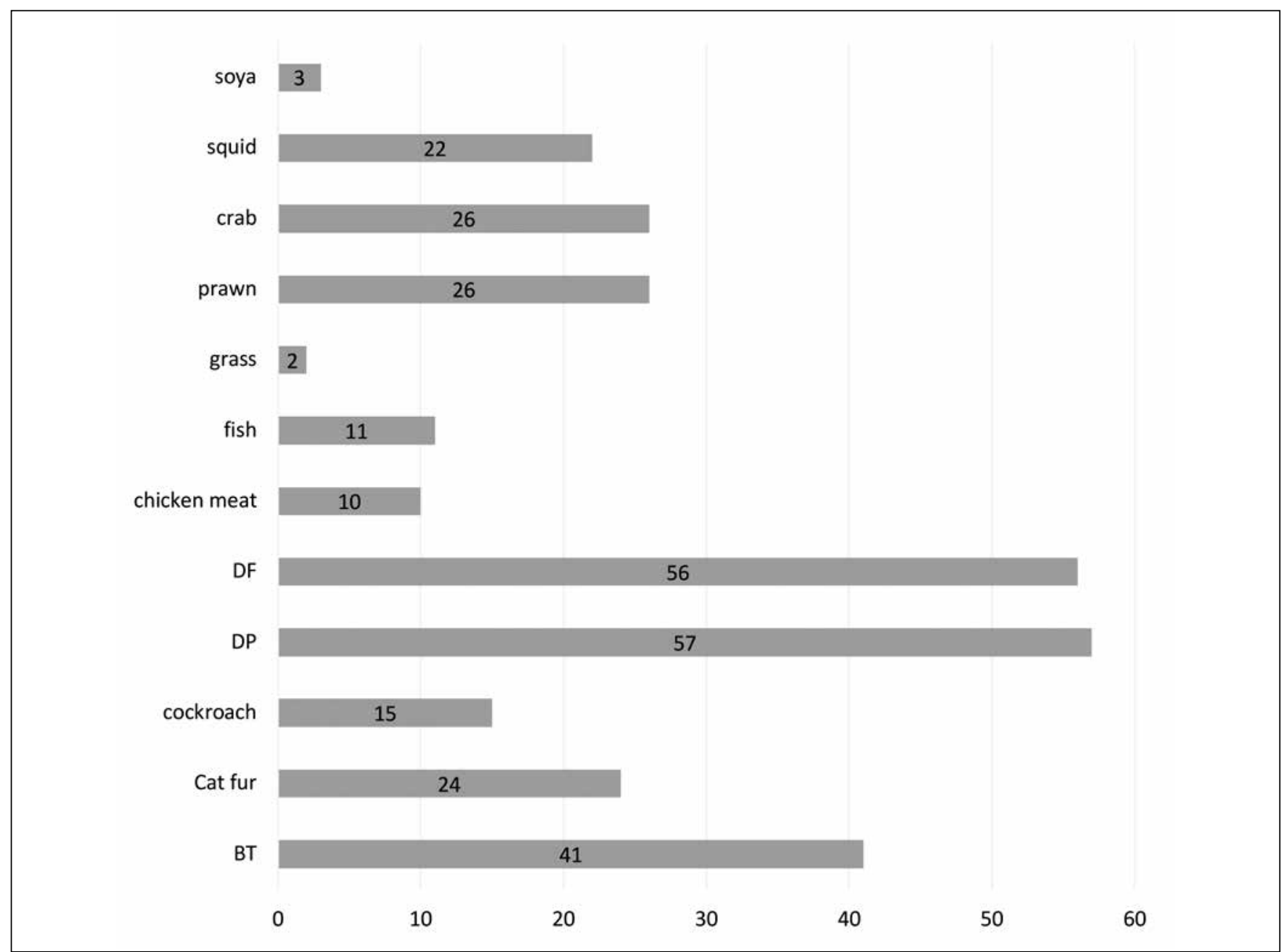


Table III - Hearing threshold in Visit 1 and Visit 2.

\begin{tabular}{|c|c|c|c|c|c|}
\hline \multicolumn{4}{|l|}{ Descriptive } & \multicolumn{2}{|c|}{ Wilcoxon signed-rank test } \\
\hline \multirow{2}{*}{ Frequency $(\mathrm{Hz})$} & \multirow{2}{*}{$\begin{array}{l}\text { Right }(n=117) \\
\text { Left }(n=113)\end{array}$} & \multicolumn{2}{|l|}{ Mean (SD) } & \multirow[b]{2}{*}{ Mean Rank } & \multirow[b]{2}{*}{ p-value } \\
\hline & & Visit 1 & Visit 2 & & \\
\hline \multirow[t]{2}{*}{250} & $\mathrm{R}$ & $33.38(12.96)$ & $28.50(12.87)$ & 42.23 & $<0.0001$ \\
\hline & $\mathrm{L}$ & $33.32(13.10)$ & $29.03(13.62)$ & 47.20 & $<0.0001$ \\
\hline \multirow[t]{2}{*}{500} & $\mathrm{R}$ & $33.50(12.22)$ & $29.79(12.97)$ & 46.89 & $<0.0001$ \\
\hline & $\mathrm{L}$ & $33.75(12.84)$ & $30.31(13.25)$ & 44.73 & 0.001 \\
\hline \multirow[t]{2}{*}{1000} & $\mathrm{R}$ & $32.74(12.86)$ & $28.29(13.17)$ & 43.00 & $<0.0001$ \\
\hline & $\mathrm{L}$ & $33.41(13.05)$ & $30.66(14.28)$ & 38.85 & $<0.0001$ \\
\hline \multirow[t]{2}{*}{2000} & $\mathrm{R}$ & $29.36(12.20)$ & $25.00(12.46)$ & 45.06 & $<0.0001$ \\
\hline & $\mathrm{L}$ & $30.00(12.54)$ & $27.39(13.11)$ & 39.50 & 0.021 \\
\hline \multirow[t]{2}{*}{4000} & $\mathrm{R}$ & $28.76(13.80)$ & $25.98(13.02)$ & 44.59 & 0.029 \\
\hline & $\mathrm{L}$ & $29.47(13.45)$ & $26.73(14.09)$ & 43.66 & 0.007 \\
\hline \multirow[t]{2}{*}{8000} & $\mathrm{R}$ & $28.68(12.34)$ & $24.70(12.16)$ & 47.84 & 0.001 \\
\hline & $\mathrm{L}$ & $28.76(12.53)$ & $25.97(14.03)$ & 46.09 & 0.002 \\
\hline
\end{tabular}

in the left ear were $29.03 \mathrm{~dB}$ (13.62), $30.31 \mathrm{~dB}$ (13.25), 30.66 $\mathrm{dB}$ (14.28), 27.39 dB (13.11), $26.73 \mathrm{~dB}$ (14.09) and 25.97 $\mathrm{dB}$ (14.03), respectively. There were significant differences for mean hearing threshold across tested frequency for right and left ears in Visit 1 and Visit 2. It showed that the hearing level significantly improved during Visit 2 . From our study, we found that $500 \mathrm{~Hz}$ was the most vulnerable frequency which showed high hearing level of $33.50 \mathrm{~dB}(\mathrm{p}<0.0001)$. The low frequency hearing threshold was significantly affected compared to high frequency hearing threshold (table III).

The hearing threshold of children with OME with AR and non-AR was analyzed. The mean and standard deviation of 250 $\mathrm{Hz}, 500 \mathrm{~Hz}, 1 \mathrm{k}, 2 \mathrm{k}, 4 \mathrm{k}$ and $8 \mathrm{k}$ in the right ear of AR children were 36.35 (13.08), 35.63 (12.45), 35.24 (13.08), 31.51 (12.36), 31.51 (12.78). The mean and standard deviation of $250 \mathrm{~Hz}, 500 \mathrm{~Hz}, 1 \mathrm{k}, 2 \mathrm{k}, 4 \mathrm{k}$ and $8 \mathrm{k}$ in the left ear of AR children were 34.92 (13.59), 35.75 (12.87), 35.46 (13.85), 32.08 (12.40), 31.46 (14.51), 31.08 (12.88) (table IV). The mean and standard deviation of $250 \mathrm{~Hz}, 500 \mathrm{~Hz}, 1 \mathrm{k}, 2 \mathrm{k}, 4 \mathrm{k}$ and 8 $\mathrm{k}$ in the right ear of non-AR children were 29.91 (12.03), 31.02 (11.54), 29.81 (12.05), 26.85 (11.62), 25.56 (13.37), 25.37 (11.02). The mean and standard deviation of $250 \mathrm{~Hz}, 500 \mathrm{~Hz}$, $1 \mathrm{k}, 2 \mathrm{k}, 4 \mathrm{k}$ and $8 \mathrm{k}$ in the left ear of non-AR children were 31.15 (12.21), 31.04 (12.41), 30.63 (11.42), 27.19 (12.28), 26.77 (11.26), 25.63 (11.42). We found that there were significant differences between these two groups and conclude that children with OME and AR had a significant higher hearing threshold compared to non-AR (table IV).

\section{Discussion}

Otitis media with effusion is an inflammatory process in the middle ear, which can occur as acute or chronic with a collection of non-purulent fluid behind the intact tympanic membrane. It is the most frequent cause of hearing loss in children and the most common reason for surgery (16).

In our study, the highest prevalence of OME was among children between the ages 4-8 (53\%) and it tends to decrease in later ages. Our result was consistent with other studies, in which age was a risk factor for OME. Al-Humaid reported in their multivariate regression model, there was a statistically significant correlation between OME and age less than 8 years $(\mathrm{p}<$ 0.0001; OR = 5.052, 95\% CI: 3.289 - 7.762) (17).

A number of studies reported a high prevalence of AR in children with OME. The prevalence of AR in OME children in our study was $52.3 \%$. In a study conducted by Jordan et al, he reported that $74 \%(91 / 123)$ children with OME had allergic rhinitis (18). Lecks et al tested 82 children with OME using skin prick test and found that $72(88 \%)$ of children had positive results. Alles et al reported $89 \%$ prevalence of AR in the OME children (8). In a recent study done by Pau and $\mathrm{Ng}, 7.5 \%$ of the AR group were found to have OME compared with $1.6 \%$ in the non-AR group $(p=0.016)$. Their study showed a significant difference in the prevalence of OME between AR and non-AR subjects (10). The eustachian tube dysfunction is the most probable mechanism that can cause middle ear effusion. In children with $A R$, inflammation over the eustachian tube lining results in a 
Table IV - Comparison of Hearing Level between OME Children with AR and non-AR.

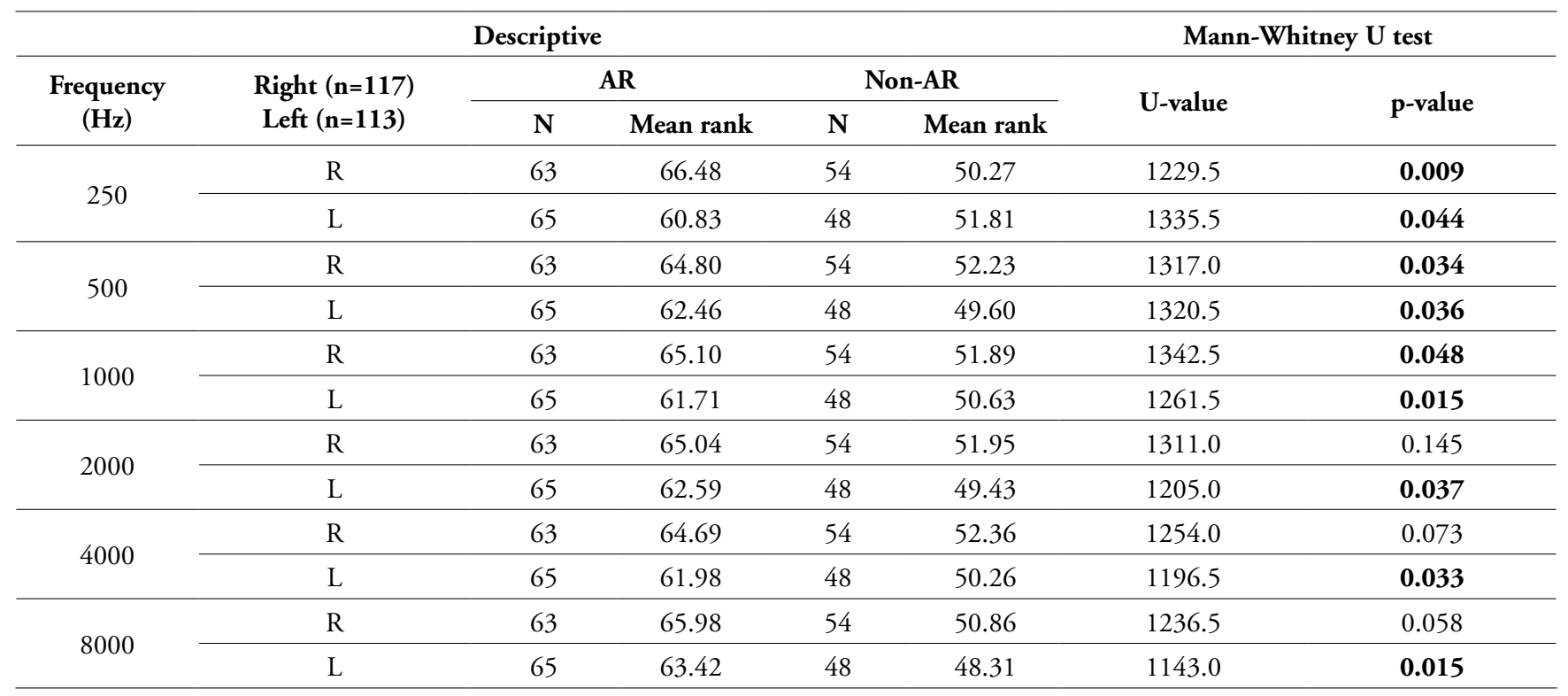

negative middle ear pressure. Cytokines were assumed to be responsible among the inflammatory regulators of the middle ear inflammation of chronic OME (19). The role of allergy in persistent OME has been proposed following several mechanisms: 1 , inflammation of the middle ear mucosa; 2 , the inflammatory process of the eustachian tube; 3 , nasal obstruction due to the inflammatory process; 4 , aspiration of bacteria-laden allergic nasopharyngeal secretion into the middle ear cavity (20).

In this prospective study, we followed up 130 children with OME in 3 months duration. We found that 71 out of $130(54.6 \%)$ children had persistent OME and 59 (45.4\%) children had resolved OME. Pau and Ng reported, 85.7\% of OME children showed resolution at 3 months follow up. However, in their study, the number of subjects at follow-up was too small to show any statistical differences in the rate of OME resolution (10). Rosenfeld found that OME of unknown duration had 28\% spontaneous resolution by 3 months ( $95 \%$, CI $14-41 \%$ ), rising to $42 \%$ by 6 months (21). A higher percentage of resolution in our study was due to the use of intranasal corticosteroid and oral antihistamine in children with AR. Furthermore, the patients and guardian were counseled on the compliance of the medications.

We also found that 57 out of $71(80.3 \%)$ children with persistent OME had allergic rhinitis. This indicates that allergy probably plays an important role in chronic or persistent OME rather than uncomplicated OME. Tracy et al reported the incident of atopy was $24 \%$ in a study of 59 children with persistent OME (22). Species of house dust mites that triggers atopy differs according to georgraphical location It is also influenced by the temperature and humidity of the country. The top 3 commonest dust mites reported in our study: Dermatophagoides pteronyssinus (DP), Dermatophagoides farinae (DF) and Blomia tropicalis are also the most common house dust mite species in Southeast Asia. Studies reported that they are sensitizing allergens among Malaysians and Singaporeans (13).

The studied risk factors on developing persistent OME is a large family household. Our study supported the findings of other studies in which children with persistent OME significantly had a larger number of family members in the household compared to non-persistent OME children $(p=0.04)$. Al-Humaid reported from their multivariate regression model, they found that family size of more than 4 members is one of the strongest predictors of $\mathrm{OME}(\mathrm{OR}=4.192,95 \% \mathrm{CI}: 2.033$ - 8.643) (17). In Australia, Jacoby, found a higher incidence of persistent OME in Aboriginal children and they highlighted the need to reduce the crowding in the Aboriginal household (23). Other risk factors such as the history of $\mathrm{AOM}$, tonsillitis, exposure to smoking or passive smoking, duration of breastfeeding and gender were not significant in this study.

Otitis media with effusion related hearing loss is the most important issues in childhood. Although the degree of hearing loss has been repeatedly labeled as "mild to moderate", a specific frequency has seldom been reported. In our study, we studied the full-range frequency specific pure tone audiometry. The average hearing thresholds calculated based on $250 \mathrm{~Hz}, 500 \mathrm{~Hz}, 1 \mathrm{kHz}$, $2 \mathrm{kHz}, 4 \mathrm{kHz}$, and $8 \mathrm{kHz}$ are shown in table III. We found that OME produced a hearing loss up to $33 \mathrm{~dB}$ (mild hearing loss). 
We also found that configuration of hearing loss is much more affected at low frequency. Previous experimental studies found that the primary mechanism in hearing loss at low frequencies is due to a reduction of the admittance of the middle-ear airspace due to the displacement of air with fluid (24).

In this study, there was a statistically significant in the improvement of the hearing threshold after 3 months of treatment. We found that, even though the OME had not fully resolved, the hearing level in these children were improved. Thus, we recommend that we should give longer watchful waiting time for the OME children with AR in view of there is a chance for improvement in the subsequent visit. Unnecessary surgery in this group of children can be avoided with optimum medical treatment.

Our study is different from others as we treated and we advised on the compliance of medications and we followed them up closely for 3 months to see the progression. Regarding the hearing assessment, we tested throughout all the frequency of hearing level and not just labelled "mild to moderate hearing loss", as we might miss the undetected improvement of the hearing level in a certain frequency. We also excluded the children with grade 4 adenoid enlargement as this is the confounding factor for persistent OME, so that we can prove the persistent OME is purely due to AR.

\section{Conclusions}

There is a high prevalence rate of AR among children with OME which clarifies their association as intended by one of the objectives of this study. Allergic rhinitis children with OME had

\section{References}

1. Gates GA, Klein JO, Lim DJ, et al. Recent advances in otitis media. 1. Definitions, terminology, and classification of otitis media. Ann Otol Rhinol Laryngol Suppl 2002; 188:8-18.

2. Suzuki M, Mogi G. A link between allergic rhinitis and otitis media with effusion. Allergol Int 1998; 47(3):177-182. doi:10.2332/ allergolint.47.177.

3. Gultekin E, Develioğlu ON, Yener M, Ozdemir I, Külekçi M. Prevalence and risk factors for persistent otitis media with effusion in primary school children in Istanbul, Turkey. Auris Nasus Larynx 2010; 37(2):145-149. doi:10.1016/j.anl.2009.05.002.

4. Saim A, Saim L, Saim S, Ruszymah BH, Sani A. Prevalence of otitis media with effusion amongst pre-school children in Malaysia. Int J Pediatr Otorhinolaryngol 1997; 41(1):21-28.

5. Malaysia IFPH Ministry of Health. Findings of the National Hearing and Ear Disorders Survey. Institut Kesihatan Umum; 2009.

6. Ministry of Health Malaysia, Malaysia Society of Otorhinolaryngologists Head \& Neck Surgeons (MSO-HNS), Academy of Medicine Malaysia. 2012. Clinical practice Guideline. Management of Otitis Media with effusion in children.

7. Fernandez AA, Mcgovern JP. Secretory otitis media in allergic infants and children. South Med J 1965; 58:581-586.

8. Alles R, Parikh A, Hawk L, Darby Y, Romero JN, Scadding G. The prevalence of atopic disorders in children with chronic otitis media significant hearing loss compared to non-AR children with OM and the threshold improved significantly with medical therapy.

\section{Study implications}

We should optimize and counsel the patients and parents regarding the compliance of medical treatment for OME with AR to avoid. Children with persistent moderate to severe AR should be screened for OME and hearing assessment should be performed as they have higher tendency for developing hearing impairments. We should give longer watchful waiting time for OME children with AR before we embark on surgery.

\section{Recommendation}

We can improve our study by investigating the speech perception in noise as well as in quite using standardized test procedure to give improved "real world" understanding of the effects of OME on hearing abilities.

\section{Study limitation}

This is a prospective study which required follow up period of 3 months. In view of that, there was a high dropout rate in this study. We should recruit the control group (non OME children) to have a better comparison. Due to the budget limitation, we were unable to perform SPT in all OME children hence it was only done in AR children.

with effusion. Pediatr Allergy Immunol Off Publ Eur Soc Pediatr Allergy Immunol. 2001;12(2):102-106.

9. Passali D, Passali GC, Lauriello M, Romano A, Bellussi L, Passali FM. Nasal Allergy and Otitis Media: A real correlation? Sultan Qaboos Univ Med J 2014; 14(1):e59-64.

10. Pau BC, $\mathrm{Ng}$ DK. Prevalence of otitis media with effusion in children with allergic rhinitis, a cross sectional study. Int J Pediatr Otorhinolaryngol 2016; 84:156-160. doi:10.1016/j.ijporl.2016.03.008.

11. Relation of Audiograms to the Impedance Formula: Acta Oto-Laryngologica: Vol 36, No sup74. https://www.tandfonline.com/ doi/abs/10.3109/00016484809131988?journalCode=ioto20. Accessed May 1, 2018.

12. Rosenfeld RM, Schwartz SR, Pynnonen MA, et al. Clinical practice guideline: Tympanostomy tubes in children. Otolaryngol--Head Neck Surg Off J Am Acad Otolaryngol-Head Neck Surg 2013; 149(1 Suppl):S1-35. doi:10.1177/0194599813487302.

13. Zahedi FD, Gendeh BS, Husain S. Sensitisation to common allergens in children with allergic rhinitis. Brunei Int Med J 2011; 7(4):200-206.

14. Cassano P, Gelardi M, Cassano M, Fiorella ML, Fiorella R. Adenoid tissue rhinopharyngeal obstruction grading based on fiberendoscopic findings: a novel approach to therapeutic management. Int J Pediatr Otorhinolaryngol 2003; 67(12):1303-1309. 
15. 2008-ARIA-PG-View-WM.pdf. https://www.euforea.eu/assets/ pdfs/aria/2008-ARIA-PG-View-WM.pdf. Accessed July 24, 2018.

16. Zernotti ME, Pawankar R, Ansotegui I, et al. Otitis media with effusion and atopy: is there a causal relationship? World Allergy Organ J 2017; 10(1). doi:10.1186/s40413-017-0168-x.

17. Humaid A-HI, Ashraf A-HS, Masood KA, Nuha A-HS, Saleh ADA, Awadh AM. Prevalence and risk factors of Otitis Media with effusion in school children in Qassim Region of Saudi Arabia. Int J Health Sci 2014; 8(4):325-334.

18. Jordan R. Chronic secretory otitis media. The Laryngoscope 1949; 59(9):1002-1015. doi:10.1288/00005537-194909000-00004.

19. Smirnova MG, Birchall JP, Pearson JP. The immunoregulatory and allergy-associated cytokines in the aetiology of the otitis media with effusion. Mediators Inflamm 2004; 13(2):75-88. doi:10.108 $0 / 09629350410001688477$.

20. Döner F, Yariktas M, Demirci M. The role of allergy in recurrent otitis media with effusion 2004; 14:5.
21. Rosenfeld RM, Kay D. Natural history of untreated otitis media. The Laryngoscope 2003; 113(10):1645-1657.

22. Tracy JM, Demain JG, Hoffman KM, Goetz DW. Intranasal beclomethasone as an adjunct to treatment of chronic middle ear effusion. Ann Allergy Asthma Immunol Off Publ Am Coll Allergy Asthma Immunol 1998; 80(2):198-206. doi:10.1016/S10811206(10)62956-0.

23. Jacoby P, Carville KS, Hall G, et al. Crowding and other strong predictors of upper respiratory tract carriage of otitis media-related bacteria in Australian Aboriginal and non-Aboriginal children. Pediatr Infect Dis J 2011; 30(6):480-485. doi:10.1097/ INF.0b013e318217dc6e.

24. Handi J, Radi B, Bagatin T, Savi A, Stambolija V, Nevajda B. Hearing in Children with Otitis Media with Effusion - Clinical Retrospective Study. Coll Antropol 2012:5. 